\title{
Verdien Homo naledi 'n plek in ons familie-album? 'n Teologiese besinning oor die evoluering van spiritualiteit met spesifieke verwysing na die begraafplaasteorie van Lee Berger en die 'Rising-Star'-ekspedisie
}

Author:
Kobus Pienaar ${ }^{1}$ -
Affiliation:
'Reformed Theological
College, Faculty of Theology,
University of Pretoria,
South Africa
Research Project Registration:
Project Leader: A. Ungerer
Project Number: 82329542
Description:
This research is part of the
project, 'Contextualized
Reformed Theology in South
Africa', directed by Dr Andre
Ungerer of the Reformed
Theological College, Faculty
of Theology, University of
Pretoria.
Corresponding author:
Kobus Pienaar,
ajpienaar1@gmail.com
Read phone or
Dates:
Received: 27 June 2017
to read online.
Accepted: 26 Aug. 2017
Published: 06 Dec. 2017
How to cite this article:
Pienaar, K., 2017, 'Verdien
Homo naledi ' $n$ plek in ons
familie-album? ' $n$ Teologiese
besinning oor die evoluering
van spiritualiteit met
spesifieke verwysing na die
begraafplaasteorie van Lee
Berger en die 'Rising-Star'-
ekspedisie', HTS Teologiese
Studies/Theological Studies
org/10.4102/hts.v73i1.4720

The discovery of a new homonin species called Homo naledi evoked unprecedented interest, even outside the scientific disciplines who are researching extinct homonin species. The reason for this is that Prof. Lee Berger, attached to the University of the Witwatersrand and his team, known as the Rising Star-expedition, came to the conclusion that the fossils that were discovered in the Dinaledi cave room in Sterkfontein outside Johannesburg in 2013, were placed there deliberately. The theory postulates the possibility of symbolic or ritual behaviour by a species that lived and later became extinct approximately 1 to 2 million years ago. If this is indeed the case, it also offers theologians the opportunity to join the conversation with regard to the evolvement of our spirituality and religiousness. This article is an attempt to render a contribution, with the data available to us, about the value of the prehistoric signs of spirituality with specific reference to the so-called cemetery theory. Together with this, other usable theories will be employed to consider the possible signs of ritual and symbolic behaviour by Homo naledi. The condition for a meaningful discussion about the evolvement of our spirituality and religiousness is that epistemological contours be clearly drawn. With the first part of the article these contours are drawn and with the second part the possible implications of the cemetery theory are reviewed.

\section{Inleiding: Op 'n persoonlike noot}

Die bekendstelling van 'n onbekende homonine spesie genaamd Homo naledi op 10 September 2015 tydens 'n perskonferensie te Maropeng, Wieg van die Mensdom, Johannesburg, deur die Rising Star-ekspedisie bestaande uit wetenskaplikes van regoor die wêreld o.l.v. die bekroonde paleo-antropoloog, prof. Lee Berger, was 'n media sensasie. Ek kon my kinderlike opgewondenheid kwalik in bedwang hou, aangesien ek goed bekend is met die omgewing waar die fossiele ontdek is, en ek uit blote belangstelling myself oor die jare op hoogte van die jongste palaeontologiese ontdekkings probeer hou het. Dié ontdekking het my laat terugdink aan die dae toe ek as jong knapie oor dieselfde rante geloop en klippe omgekeer het op soek na skerpioene, slange en ander verrassings waar Homo naledi waarskynlik 1 tot 2 miljoen jaar gelede besig was met dieselfde aktiwiteit, op soek na kos. Ek was en is steeds predikant in gemeentes in die omgewing van Sterkfontein, Swartkrans en Kromdraai waar daar sedert 1936 opgrawings gedoen word o.l.v. groot name soos Raymond Dart, Robert Broom, Phillip Tobias en nou Lee Berger, om maar net 'n paar te noem. Hoewel daar gedurende die Tweede Wêreldoorlog 'n onderbreking in die opgrawings was, het hierdie gebied, tans bekend as die Wieg van die Mensdom (Cradle of Humankind), sy plek as een van die belangrikste hominine fossiele-terreine ter wêreld ingeneem. Gedurende die jaar 2000 is dié gebied deur UNESCO tot Wêrelderfenisgebied verklaar. Heelwat van my lidmate het hier gewoon en woon steeds in die Swartkrans- en Sterkfonteinomgewing - die meeste van hulle boere uit 'n konserwatiewe Afrikanergemeenskap.

Tydens pastorale besoeke aan lidmate in die omgewing, het van hulle dikwels aan my meegedeel dat argeoloë, geoloë en amateurs wat in fossiele belangstel op hulle plase ronddwaal op soek

Copyright: @ 2017. The Authors. Licensee: AOSIS. This work is licensed under the Creative Commons Attribution License. 
na ou beendere. Verder was een van my pastorale take om van my afgestorwe lidmate in die Sterkfontein-begraafplaas ter ruste te lê-skaars 'n klipgooi van die Rising Star-grot wat skielik as die wêreld se oudste begraafplaas bekendheid verwerf het. Die ontdekking van fossiele en argeologiese aktiwiteite in die omgewing waar ek grootgeword het en lank pastoraal gewerk het, het dikwels gelei tot warm tafelgesprekke oor ons herkoms. Dit kan in die woorde van een van my destydse lidmate opgesom word: 'Dominee, hoe reken jy, kom ons oorspronklik uit die tuin van Eden of hier uit die grotte op my plaas?' Hoewel die vraag in leketaal gestel is, sny dit tot op die been van postmoderne Christene se beskouing oor ons herkoms. Wat my betref, is dit ' $n$ vraag wat geen teoloog kan vermy nie. Dit het my gedwing om met kritiese oë vanuit my teologiese tradisie na die Bybel, sowel as na die fossielevondse te kyk.

\section{Kenteoretiese vertrekpunt}

Die denkklimaat waarbinne ek grootgeword en ook teologies gevorm is, het na my wete selde indien ooit epistemologies rekening gehou met die bydrae van palaeontologiese navorsing sedert 1936 wat so te sê op ons voorstoep plaasgevind het. Hervormde teologie en palaeontologie het op hoë uitsonderings na soos treinspore op parallelle trajekte beweeg. Die rede hiervoor, spesifiek binne my teologiese dampkring, skryf ek grootliks toe aan die invloed wat Karl Barth se openbaringsteologie op ons teologie uitgeoefen het. Barth het nie die nodigheid van ' $n$ interdissiplinêre debat met die natuurwetenskappe oor ons verhouding met God ingesien nie en daarby was die vraag na ons herkoms ingesluit. Barth was skepties oor die waarde van natuurwetenskappe in teologie, aangesien hy oortuig was dat God as die Gans Andere nooit tot 'n objek vir menslike denke gereduseer kan word nie. In Barth se poging om die mens se beperkte vermoë om by wyse van die rede outentieke kennis van God te bekom, uit te wys, het Barth die kennisinsette wat ander dissiplines op teologie kan uitoefen, as irrelevant beskou. In die radikale onderskeid wat Barth tussen God en mens, genade en natuur, openbaring en religie, geloof en kennis wou tref, het hy vasgeval in wat Wenzel van Huyssteen beskryf as 'n openbaringspositiwisme (Van Huyssteen 1987:23). So is die teologiese deure van die dialektiese teologie vir lank gesluit gehou vir die waardevolle navorsing wat deur paleontoloë op Suid-Afrikaanse bodem m.b.t. ons herkoms gedoen het. Wat my betref, is 'n sagte kreasionistiese standpunt gehandhaaf, hoewel Hervormde teologie nooit op 'n literalistiese of fundamentalistiese wyse stelling ingeneem het teenoor palaeontologiese resultate nie.

Met hierdie artikel volg ek 'n kenteoretiese invalshoek wat volledig en ongereserveerd oop staan vir 'n diskoers met wetenskaplike dissiplines t.o.v. ons herkoms. Trouens, ek bepleit ' $n$ interdissiplinêre werkswyse as die engiste roete tot 'n teologie wat met intellektuele integriteit kan spreek tot 'n postmoderne geloofsgemeenskap.

Ek sal dus poog om vanuit my dissipline, tradisie en vooroordele my te laat bedien deur palaentologie en neuro- psigologie in ' $n$ beskeie poging om die beendere-tekste van my waarskynlike oervoorouers uit die Dinaledi-grotkamer tot my te laat spreek.

Verder is ek oortuig dat konfessionele absolutisme, soos fundamentalisme, 'n doodskoot is vir 'n sinvolle gesprek oor die onderwerp. Die engiste wyse waarop daar sprake kan wees van vordering m.b.t. die interdissiplinêre gesprek oor ons voorgeskiedenis asook die evolering van ons religieusiteit, is wanneer daar 'n pluriforme platform geskep word vir veelvuldige interpretasies wat mekaar aanvul, eerder as uitsluit. Die kenteoretiese klem val dus op wil-tot-begrip eerder as wil-tot-beheer.

Die afgelope een en 'n half eeu sedert die verskyning van Darwin se Origin of Species, getuig van vele onsmaaklike skermutselings tussen teologie en die wetenskap oor die evolering van lewe en lewensvorme, waar die agenda veel eerder bepaal is deur ' $n$ strewe om gesag af te dwing, in stede van 'n strewe na begrip en insig (2015:244). Vir die teoloog wat dus erns wil maak met palaeontologiese navorsing, insluitende die opwindende moontlikhede wat 'n vonds soos Homo naledi bied, sou dit dus in Wenzel van Huyssteen se woorde 'a fall from epistemological innocence' beteken. In sy boek The shaping of Rationality (1999) stel Van Huyssteen voor dat die teoloog ter wille van 'n sinvolle dialoog oor ons herkoms behoort te ontsnap uit wat hy tipeer as epistemiese isolasie. Trouens, indien mens die stelling aanvaar dat alle vorme van lewe asook die uitdrukkingsvorme daarvan evoleer, impliseer dit immers ook dat teorieë oor ons herkoms, insluitende 'n teologiese beskouing daarvan, oop staan vir hersiening. Donald T. Campbell gebruik hiervoor die term 'evolutionary epistemology'. Van Huyssteen (2004) stel dit so:

Evolutionary epistemology thus reveals the process of evolution as a holistic, embodied belief-gaining process, a process that in humans too, is shaped preconsciously. All our beliefs, also our religious beliefs, thus have distant evolutionary origins. (p. 38)

\section{'n Hermeneutiese handvatsel vir die skeppingsverhale volgens Genesis 1 en 2 , wat die gesprek met palaeontologie behoort te akkommodeer}

Aangesien die fokus van hierdie artikel elders lê, sal ek slegs baie kortliks aandag skenk aan lewensvatbare eksegetiese moontlikhede t.o.v. die skeppingsverhale volgens Genesis asook die imago dei-konsep wat 'n interdissiplinêre gesprek met antropoloë asook paleontoloë moontlik maak.

Tot voor die Aufklärung het mense se beskouing oor ons herkoms uit 'n amalgaam van klassieke filosofie, Christelike teologie en 'n prewetenskaplike kosmogonie bestaan. Die invloed van die Griekse filosofie, veral Plato se idealisme en die teleologie van Aristoteles oor die Christelike beskouing van ons herkoms, moet nie onderskat word nie. Plato se dualistiese verstaan van die werklikheid, nl. dat die vorm 
slegs 'n benaderde afbeelding uitmaak van 'n suiwere, hoër idee, het aanleiding gegee tot die teologiese en filosofiese beskouing dat die werklikheid slegs 'n voorlopige onvolmaakte manifestasie van 'n voorafbedinkte meesterplan is. Aristoteliaanse teleologie wat daarop neerkom dat die verskynsel slegs verstaan kan word indien die doel 'telos' daarvan ingesien word, is veral deur skolastiese teoloë soos Tomas Aquinas, sorgvuldig ingespan om 'n groter meesterplan agter die skepping te konseptualiseer.

Die teoretiese fisikus, Carlo Rovelli, toon in sy boek Reality is not what it seems. The Journey to Quantum Gravity (2016) dui oortuigend aan dat die kerkvaders veel groter aansluiting gevind het by Plato se dualisme en Aristoteles se teleologie, as by die atomis Democritus wat reeds teen 300 v.C. op 'n naturalistiese en evolusionêre wyse na die skepping gekyk het. Rovelli som Democritus se atomistiese filosofie soos volg op:

According to Democritus, there is no finality. No purpose in this endless dance of atoms. We, just like the rest of the natural world, are one of the many products of this infinite dance. Nature continues to experiment with forms and structures, and we are the products of selection. (Rovelli 2016:21)

Dis egter merkwaardig hoe naby Democritus reeds 2300 jaar gelede aan Darwin se insigte gekom het. Die kreasionistiese weerstandigheid op die evolusie-teorema is dus nie slegs te wyte aan 'n literalistiese interpretasie van die skeppingsverhale vanuit fundamentalistiese oorde nie, maar vanweë 'n prekondisionering deur Plato en Aristoteles se kenteoretiese modelle. Wat my betref, is daar 'n duidelike aksentverskil tussen teologie gebaseer op Platoniese idealisme en Arestoteliaanse teleologie en die kosmogonie van die outeurs van die 'P-bron' en 'J-bron' in Genesis 1 en 2.

Ek stem saam met Karen Amstrong (2011:56) wanneer sy stel: 'Genesis is a meditation upon the nature of being itself'. Volgens die ' $\mathrm{P}$ '-bron (Gen. 1), is daar 'n sublieme krag onderliggend aan die werklikheid waarvoor die mens in verwondering staan. Vir ' $\mathrm{P}$ ' gaan dit dus oor verwondering eerder as verklaring. Die 'J'-bron (Gen. 2) aan die ander kant, plaas heelwat meer klem op die mens se verbintenis met die aarde. (Die mens vanuit die stof van die aarde.) Volgens Amstong gaan dit vir 'J' eerder oor kontinuïtiet met die natuur en ander lewe as diskontinuiteit soos dit tot uitdrukking kom in die imago dei-metafoor in ' $\mathrm{P}$ ' se geval. Daar bestaan volgens Amstrong nie by ' $\mathrm{J}$ ' so 'n duidelike kwalitatiewe onderskeid tussen mens en natuur soos wat ons by ' $\mathrm{P}$ ' met sy imago dei-metafoor aantref nie. Hierdie intertekstuele spanning tussen die twee skeppingsverhale in Genesis dui op 'n voorwetenskaplike, perspektivistiese interpretasie van ons ontstaan. Kan dit wees dat ' $\mathrm{P}$ ' se imago dei-metafoor, versterk deur die lense van Plato en Aristoteles aanleiding gegee het tot ' $n$ antropologie wat die mens ontologies op 'n ander vlak plaas, met die gevolg dat die mens se uniekheid binne die Westerse teologie oor eeue oorbeklemtoon is?
Met die bovermelde kernteoretiese en eksegetiese kantaantekeninge, sal ons dit nou waag om die Dinaledi-grot met teologiese stewels binne te gaan.

\section{Die oorweging van die begraafplaas- hipotese soos gepostuleer deur Lee Berger en die Rising Star-ekspedisie}

Dit is die sogenaamde begraafplaasteorie wat Homo naledi oornag 'n mediasensasie gemaak het. Die blote gedagte dat 'n oerspesie wat waarskynlik 1 tot 2 miljoen jaar gelede geleef het, 'n primitiewe ritueel rondom hul dooies kon uitvoer, gryp die verbeelding aan. Kwessies oor nie slegs ons biologiese herkoms nie, maar veral die evolusie van ons kognitiewe vermoëns en daarby ingesluit ons spiritualiteit en religieusiteit, kom aan die orde, indien die hipotese van simboliese gedrag by Homo naledi aanvaar word. Hoewel toonaangewende palaeontoloë soos professore Tim White (Universiteit van Berkeley), Christoph Zollikofer (Universiteit van Zürich) en Jeffrey Schwartz (Universiteit van Pittsburgh) die hipotese van prof. Lee Berger en sy navorsingspan verwerp, kon daar tot op hede nie 'n ander verklaring gebied word vir die tafonomiese konteks van die naledi-vonds nie. Deeglike geologiese toetse dui daarop dat die grotkamer nie ouer as 3 miljoen jaar is nie en verder is daar geen geologiese aanduidings dat daar ooit ' $n$ ander opening na die Dinaledikamer bestaan het nie. 'n Multidissiplinêre span kundiges oor 'n wye front wat deel uitgemaak het van die Rising Starekspedisie, kom dus tot die gevolgtrekking dat die beendere daar met opset geplaas is, tot die teendeel bewys kan word.

Patrick S. Randolph-Quinney (2015) maak, wat my betref, die waardevolle opmerking in sy artikel 'The mournful ape: Conflating expression and meaning in the morturary behaviour of Homo naledi' naamlik dat die probleem veel eerder op 'n semantiese vlak lê. Volgens Randolph-Quinney lei die teorie van 'n prehistoriese begraafplaas tot assosiasies met menslike gedrag gevul met antroposentriese simboliek. Wat ons volgens Randolph-Quinney nie uit die oog moet verloor nie is dat ons objek van ondersoek 'n uitgesterfte spesie is wat veel eerder dierlike as menslike gedrag getoon het.

Paul Pettit se boek 'The Palaeolithic origins of Human Burial' (2011) kan hier van waarde wees. Pettit beskryf in die boek die verskille tussen die treur-, verlies- en afskeidneempatrone by sjimpansee-kolonies aan die een kant en mense se belewenis van die dood van naasbestaandes aan die ander kant. Hoewel sjimpansees en bonobo's (ons naaste familie in die diereryk), asook olifante duidelik uitdrukking gee aan 'n bepaalde belewenis wanneer hulle in kontak kom met ' $n$ pasafgestorwe lid van hul groep, is daar volgens hom gedragswetenskaplik nie sprake van kognitiewe diepte of selfs 'n begrip van die dood nie.

Vir die doel van dié artikel kan ons dus stel dat aangesien vele gevallestudies daarop dui dat sommige primate seremoniële gedrag toon, spesifiek met die afsterwe van 'n lid van die groep al is dit ver verwyderd van 'n menslike 
ervaring, dit nie vergesog is om te veronderstel dat Homo naledi soortgelyke gedrag kon toon nie. Om egter 'n akkurate aanduiding te gee van die kongnitiewe diepte en omvang van 'n primitiewe uitgesterfte spesie soos Homo naledi, op sterkte van wat ons aflei uit die sg. begrafnis ritueel, is egter onmoontlik. Sou daar wel sprake wees van simboliese, rituele handeling, hoe primitief ook al, verplaas dit ons wat datering betref, baie verder terug as die vroegste begrafnisrituele waarvan ons bewus is.

Die oudste waarskynlike aanduidings van 'n begraafplaas vind ons by terreine soos Atapuerca in Spanje wat die beendere van ongeveer 28 individue van die spesies Homo heidelbergensis bevat. Hierdie fossiele dateer 300000 jaar gelede. Die beendere is almal in ' $n$ put gevind en aangesien daar verskeie teorieë bestaan oor waarom die individue in die put beland het, kan daar nie sonder twyfel aanspraak gemaak word op rituele gedrag vanweë uiteenlopende teorieë wat die vonds betref nie. Die vroegste onbetwisbare aanduidings van opsetlike plasing van die oorskot van 'n afgestorwene, vind ons in Krapina Kroasië. Die beendere wat daar opgegrawe is, is dié van Homo neanderthalensis en dateer 130000 jaar gelede. Die oudste begraafplaas van Homo sapiens, waar die beendere van moontlik 'n moeder en kind met rooi oker gekleur en ter ruste gelê is, vind ons in Qafzeh, Israel. Die spesifieke fossielevonds word op 100000 jaar gelede gedateer. Indien ons die Rising Star-ekspedisie se teorie aanvaar dat die beendere van Homo naledi opsetlik in die Dinaledi-grot geplaas is, draai dit die horlosie wat die simboliese gedrag en afskeidsrituele betref, 'n miljoen jaar terug! Dit open die debat oor 'n veel langer tydperk van evolering t.o.v. simboliese, rituele gedrag, 800000 jaar voor Homo sapiens op die toneel verskyn het.

\section{Die implikasies indien praktiese aspekte oor die plasing van Homo naledi se afgestorwenes in die Dinaledi-grotkamer in ag geneem word}

Sou ons die begraafplaasteorie aanvaar, bring dit ons by die vraag naamlik hoe dit vir Homo naledi prakties moonlik was om hul dooies in 'n pikdonker onbegaanbare terrein te gaan neerlê. Veral indien ons in ag neem dat die grot waar die ontdekking gemaak is, uiters ontoegankik is. So ontoeganklik dat daar bo en behalwe die beendere van Homo naledi slegs 'n paar fossielbeendere van vlermuise en ' $n$ uil in die Dinaledigrotkamer gevind is. M.a.w. geen fossiele van roofdiere of enige ander kruipende diere nie. Verder moet ons in ag neem dat Homo naledi wat sig betref, swak aangepas was by pikdonker toestande. Die vraag onstaan dus - is daar 'n waarskynlikheid dat hulle die roete na die Dinaledigrotkamer en terug kon aflê deur gebruik te maak van een of ander vorm van lig?

Dit bring ons by die kwessie oor homonine se eerste interaksie en beheer van vuur, aangesien die beheer van vuur kon bydra tot die voorbereiding van kos, die verhitting van woon- en slaapplekke, die vervaardiging van instrumente, selfverdediging en natuurlik die verligting van donker terreine soos die uiters ontoeganklike Dinaledi-grotkamer.

Vele navorsers het reeds aangedui dat die beheer van vuur gelei het tot meer komplekse sosiale gedrag en interaksie wat geëvoleer het tot meer komplekse rituele en simboliese handeling. J.A.J. Gowlett (2016) toon in 'n artikel 'The discovery of fire by humans: a long and convoluted process', aan dat die vroegste aanduidings van die gebruik van vuur in Turkane, Kenia, die Swartkrans-grotte naby Sterkfontein en die Wonderwerkgrotte naby Kuruman, Suid-Afrika, aangetref word. Die datering van hierdie tonele van doelbewuste vuurmaak, waarskynlik deur Australopithecus, word op een miljoen jaar gelede beraam. Hoewel datering die achilleshiel van die Rising Star-ekspedisie is, kan ons egter nie die moontlikheid uitsluit dat Homo naledi die vermoë kon gehad het om vuur te beheer nie. Enige iemand wat die Dinaledi-grot betree, sal onmiddellik sien dat 'n primitiewe spesie wat vanuit 'n evolusionêre oogpunt nie visueel aangepas was by 'n pikdonker en uiters onbegaanbare onderaardse terrein nie, dit nie sonder een of ander vorm van lig sou kon doen nie. Ek het al dikwels die grotte in die omgewing besoek, o.a. die Sterkfonteingrotte wat oop is vir die publiek. Sodra die ligte afgeskakel word, is mens geheel en al gedisoriënteerd. Neem verder in ag dat die Dinaledigrot uit 80 meter uiters onbegaanbare terrein bestaan. Sonder enige vorm van lig verander die grot vinnig in ' $n$ doolhof. Hoe 'n spesie met 'n derde van die mens se breingrootte daarin kon slaag om sonder 'n ligbron 'n lewelose liggaam 80 meter ver in ' $n$ pikdonker grot te gaan neerlê en daarna weer hul weg na buite te vind, maak slegs sin indien ons aanvaar dat hulle een of ander vorm van lig kon gebruik het.

\section{Neuro-psigologiese spekulasies oor die evolusie van 'n primitiewe vorm van spiritualiteit vanweë die entoptiese verskynsel}

Prof. J. Lewis-Williams, verbonde aan die Cognitive Archaeology-departement van Wits, is 'n kenner op die gebied van Upper Palaeolithic art [Steentydperkkuns] en bekend vir sy navorsing en vele publikasies oor rotskuns in suidelike Afrika. In 'n artikel getiteld 'The signs of all Times' (1988) verduidelik hy dat die etnografiese benadering tot rotskuns, waar slegs die sosiale omstandighede en konteks in ag geneem word, nie voldoende antwoorde bied vir die interpretasie van rotskuns nie. Volgens LewisWilliams is 'n neuro-psigologiese benadering van kardinale waarde vir die interpretasie van rotskuns (Lewis-Williams 1986). Die rede vir sy neuro-psigologiese benadering is dat hy tot die konklusie gekom het dat baie van die rotskuns shamanisties van aard is. Dit beteken dat die rotskunswerke waarskynlik die artistieke uitdrukkings van iemand in 'n bewussynsverandering verteenwoordig. Lewis-Wiliams en T.A. Dowson toon in hulle studies en publikasies oortuigend aan dat ' $n$ bewussynsverandering veroorsaak kan word deur wat bekend staan as 'entoptic phenomena' (entoptiese 
ervaring). 'n Entoptiese verskynsel is 'n toestand waar die individu simbole en motiewe visueel ervaar sonder ' $n$ eksterne ligbron:

For a conservative beginning to an investigation of possible Upper Palaeolithic mental imagery, we therefore comment less on culturally informed hallucinations than on a feature of altered states completely controlled by the nervous system. (LewisWilliams \& Dowson 1988)

Lewis-Williams en T.A. Dowson vergelyk in hulle uitgebreide navorsing rotskunsmotiewe van verskillende Steentydperkgemeenskappe (Lewis-Williams \& Dowson 1988). Uit 'n verskeidenheid voorbeelde opgeteken deur Lewis-Williams en Dowson, is dit duidelik dat sekere visuele patrone universeel voorkom onder Steentydperk-gemeenskappe se dieremotiewe op rotswande. Dis gemeenskappe met uiteenlopende kulturele agtergronde sonder enige tekens of waarskynlikheid van interaksie. Lewis-Williams dui aan dat visuele patrone soos kolle, sterre, geruite patrone, sig-saglyne en sirkels universeel op diere-motiewe voorkom (1981). Hy skryf dit gevolglik toe aan die neuropsigologiese toestand wat bekend staan as die 'entoptic phenomenon' (entoptiese verskynsel). Dit is egter merkwaardig dat hierdie toestand van 'nonreal visual perception' ook by sjimpansees, bobbejane en ape onder sekere toestande voorkom.

Die vroegste navorsing m.b.t. die entoptiese verskynsel dateer reeds vanaf 1819. Navorsers soos Johannes Purkinje, Heindrich Klüver en Max Knoll was baanbrekers op dié gebied. Hierdie navorsers het vasgestel dat die entoptiese ervaring voorkom by gevalle waar pasiënte hallusinogeniese middels soos o.a. cannabis toegedien word asook wanneer die okkupitale lob in die brein gestimuleer word. Die verskynsel kom volgens hulle navorsing ook spontaan voor wanneer visuele stimulering totaal ontbreek. Die visueleeffek, ook bekend as 'phosphenes', wat veroorsaak word deur gebrek aan lig of voldoende lig, stimuleer die senuweestelsel op so 'n wyse dat die individu patrone en drogbeelde visueel ervaar hoewel dit nie bestaan nie. Hierdie ervaring gee volgens Lewis-Williams aanleiding tot wat hy tipeer as meer komplekse 'iconic visions' wat tipies voorkom by shamanistiese rituele. In die geval van die San-boesman gaan dit gepaard met swymeldanse en hallusinasies soortgelyk aan pasiënte onder die invloed van hallusinogeniese middels. Volgens Lewis-Williams het die San-boesmans hierdie ervaring ritualisties ingekleur en beskou hulle dit as 'n konsultasie met die gode. Die waarde van Lewis-Williams se resultate vir die doeleindes van hierdie artikel lê daarin dat Lewis-Williams primitiewe vorms van religie, soos bewussynsverandering, hallusinasies, swymeldanse en rotskuns, neuropsigologies begrond en dan spesifiek vanweë die entoptiese verskynsel.

Indien ons aanvaar dat Homo naledi herhaalde male en waarskynlik oor 'n lang tydperk, diep in 'n donker grot ingekruip het met of sonder ' $n$ ligbron, is die waarskynlikheid dat sekere individue 'n entoptiese ervaring kon gehad het, nie geheel en al uitgesluit nie. Veral as ons in gedagte hou dat daar bewyse bestaan dat sjimpansees met naastenby dieselfde breingrootte en sigvermoë as Homo naledi, onder soortgelyke omstandighede ook 'n entoptiese ervaring beleef. Sou ons nou spekuleer oor die moontlikheid dat Homo naledi wel so 'n ervaring kon gehad het en dat dit neurologies geïnduseer word, weens 'n gebrek aan lig of voldoende lig, kan ons die afleiding maak dat hierdie grot-avonture en moontlike begrafnisritueel van Homo naledi die vroegste aanduidings kan wees van 'n ervaring wat oor miljoene jare geëvoleer het tot ervarings van 'n bewussynsverandering wat volgens Lewis-Wiliams en ander, die vroegste voorbeelde van spirituele ervarings is. Ervarings wat met tyd geëvoleer het tot die religieuse ervarings van moderne mense. Hoewel hierdie afleiding hoogs spekulatief is, selfs prematuur aangesien die naledi-vonds 'n skamele 2 jaar aan ons bekend is, stimuleer dit tog die debat oor die lang voorgeskiedenis van ons spiritualiteit en religieusiteit vanuit 'n evolusionêr, psigo-neurologiese oogpunt.

\section{Simboliese, rituele handeling as die eerste boustene van religie}

Volgens die Franse sosioloog, Emile Durkheim, vorm kollektiewe, simboliese, rituele handeling die eerste boustene van religie. Vir Durkheim, wat heelwat navorsing gedoen het oor primitiewe godsdienste, lei 'n ritueel tot solidariteit onder die groep waar individue dan geneig is om opofferings vir mekaar te maak. Om in 'n donker ontoeganklike grot af te kruip met die enkele oogmerk om jou afgestorwenes daar te gaan weglê, verg opoffering. Volgens Durkheim se definisie van spiritualiteit kan Homo naledi se gedrag dus die eerste dowwe flitse op die radarskerm van rituele gedrag uitmaak op die lang evolusionêre trajek na religieusiteit.

Kyk ons vir 'n oomblik deur die lense van die godsdienshistorikus, Mercia Eliade, word die dowwe flits op die radarskerm dalk effens helderder. Eliade gebruik die term 'hierophanie' as die sleutel om religieuse verskynsels te verklaar. Hierophanie is volgens Eliade 'n gedrags- en kognitiewe patroon waar 'n groep bo en behalwe funksionele optrede ook simboliese handelinge uitoefen.

Om jou afgestorwenes op een plek diep in 'n ontoeganklike laberint oor en oor te gaan wegbêre, is meer as 'n funksionele handeling. Evolusionêr gesproke is dit kontraproduktief. Toon Homo naledi se gedrag die vroegste, baie primitiewe tekens van evolering tot hierofaniese gedrag?

As 'n laaste invalshoek op Homo naledi se waarskynlike rituele gedrag, verwys ek na die teorie van Ursala Goodenough (Miller2001:330). Sy klassifiseer alle godsdienste in drie kategorieë wat sy as ancestor cults, earth cults en sky cults beskryf. Vir Goodenough toon religie 'n evolusionêre trajek van ancestor cults, na earth cults tot sky cults. 'n Duidelike merker van ' $n$ 'ancestor cult' reken Goodenough, is egter om 'n emosionele konneksie met jou voorouers te behou. Die afgestorwe voorouers se oorskot word dus nie sommer vir die aasvoëls en roofdiere agtergelaat nie. Hulle kry spesiale behandeling aangesien hulle 'n sakrale invloed uitoefen vanuit die graf. Vind ons by Homo naledi die vroegste tekens van 'n 'ancestor cult'? 


\section{Slotopmerkings}

Natuurlik laat die Dinaledi-vonds ons met meer vrae as antwoorde, meer raaisels as oplossings. Maar miskien het die vonds wel iets te bied wat die lang en kronkelpad van ons biologiese sowel as ons spirituele evolering betref. Die teologiese refleksie op hierdie primitiewe spesie en hulle grot-avonture stem ons tot nadenke, al is dit net om erkenning te gee vir hulle deursettingsvermoë deur hulle dooies iewers 'n finale rusplek weg van roofdiere te bied.

Wat ons nie kan ontken nie, is dat die waarskynlikheid wel bestaan dat hierdie spesie een van die derduisende skakels in die evolusionêre ketting uitmaak, waarvan ons, Homo sapiens met ons superieure intellek, komplekse simboliese gedrag, spiritualiteit en tegnologie tans die laaste skakel vorm. Die vraag is, is ons die laaste skakel of sal ons in die verre toekoms die aflosstokkie in die evolusionêre wedloop aan ' $n$ ander spesie of spesies oorhandig? Gaan ons ook eventueel soos Homo naledi uitsterf?

Gaan ons eksploitasie van ons enigste woonplek, die aarde, en ons minagting van die ander bykans agt miljoen spesies met wie ons ' $n$ planeet deel, tot ons vernietiging lei of gaan ons ons grootste bates naamlik ons kognitiewe vermoë, ons verbeeldingskrag en spiritualiteit ten bate van alle lewe op aarde inspan? Veral wanneer ons ag slaan op die waarskuwings van o.a. gerespekteerde wetenskaplikes soos prof. Ed Wilson wanneer hy dit soos volg formuleer:

We have created a StarWars civilization, with Stone Age emotions, medieval institutions and godlike technology. We thrash about. We are terribly confused by the mere fact of our existence, and a danger to ourselves and to the rest of life. (Wilson 2012, Kindle)

Kan Christelike teologie en etiek binne hierdie scenario 'n bydrae lewer? Ek is oortuig dis nie slegs moontlik nie maar noodsaaklik - op voorwaarde dat ons plek inruim vir waardevolle interdissiplinêre bydraes o.a. palaeontologie.

Dit kan ook teologies van waarde wees om nou ten slotte die dowwe kolletjies van die fossiele en argeologiese resultate te probeer verbind. Kolletjies derduisende jare uit mekaar. Het Homo naledi tydens hulle grot-avonture entoptiese ervarings gehad? Kon Homo naledi vuur beheer? Indien wel, het dit daartoe aanleiding gegee dat alfa-mannetjies van opeenvolgende spesies duisende jare later begin het om simboliese liggaambewegings uit te voer wat antropoloë soos Lewis-Williams as swymeldanse tipeer. Het die rituele en simbole wat die gevolg was van 'n bewussynverandering later aanleiding gegee tot verbale interaksie (taal) en simboliese uitdrukkings o.a. rotskuns? Was dit die eerste saadjies van religie aangesien shamanistiese gedrag dui op 'n anderwêreldse belewenis. Was dit die vroegste voorlopers van konsultasies met die gode?

Het ons sedert daardie eerste vroeë rituele in die Dinaledigrotkamer, 'n klipgooi van waar ek woon, spiritueel en religieus geëvoleer tot 'n 'sky cult', met komplekse rituele, simbool-sisteme en diepgaande maar uiteenlopende spirituele belewenisse? Is prof. Phillip Tobias (2013) reg wanneer hy die volgende stel:

Mankind, homo sapiens, man the wise, arose from ancestors who were not men, and were not wise in the same sense man can be. Man has ascended to his present estate from one still more savage, not necessarily more vicious, but quite certainly a dumb and irrational one. The idea of the necessity of God and other thoughts that do honour to man, were alien to our remote ancestors. They arose and developed, and secured a firm hold on man's creative thought during mankind's long and toilsome ascent from animality to humanity. (p. 226)

Met dit in gedagte gee ons vir Homo naledi wel 'n plek in ons familie-album omdat ons in hulle iets van onsself herken, nie slegs morfologies, biologies nie maar in hulle gedrag herken ons ook die eerste tekens van ons komplekse kognitiewe, simboliese en ritualistiese gedrag. In John Gurche (2013) se woorde:

We probe inside the space within your skull in an attempt to learn about your thoughts. We look for signs of consciousness, and in this mirror of awareness, we wil maybe see a bit of ourselves. You are after all our physical and symbolic link to the rest of creation. (p. 3)

\section{Erkenning Mededingende belange}

Die outeur verklaar dat hy geen finansiële of persoonlike verbintenis het met enige party wat hom nadelig kon beïnvloed het in die skryf van hierdie artikel nie.

\section{Literatuurverwysings}

Amstrong, K., 2011, In the beginning, a new interpretation of genesis, Vintage, London.

Barbour, I.G., 2000, When science meets religion, HarperOne, New York.

Barrett, P., 2000, Science \& theology since copernicus, Unisa Press, Pietermaritzburg.

Brockman, J. et al., 2004, Science at the edge, 1st red., The Orion Publishing Group, Great Britain.

Darwin, C., 2009, The origin of species and the voyage of the beagle, Vintage, London. Dawkins, R., 2015, Brief candle in the dark, Transworld Publishers, London.

Dennett, D.C., Simon \& Schuster Paperbacks, New York.

Gowlett, J.A.J., 2016, 'The discovery of fire by humans: A long and convoluted process', Philosophical Transactions B 1-8. https://doi.org/10.1098/rstb.2015.0164

Gurche, J., 2013, Shaping humanity. How science, art,and imaginatoin help us understand our origins, Yale University Press.

Idea, D.D., 1995.

Kuhn, T.S., 1962, The structure of scientific revolutions, 2nd ed., The University of Chicago Press, London.

Lewis-Williams, J., 1972, 'The syntax and function of the Giant's Castle rock paintings', South African Archaeological Bulletin 27, 49-65.

Lewis-Wiliams, J., 1981, Believing and seeing: Symbolic meanings in southen San rock paintings, Academic Press, London.

Lewis-Williams, J., 1986, 'Cognitive and optical illusions in San rock art research', Anthropology 27, 171-178. https://doi.org/10.1086/203415

Lewis-Williams, J. \& Dowson, T., 1988, 'The signs of all times', The University of Chicago Press Journals 29(2).

Miller, J.B., 2001, An evolving dialogue, Trinity Press International, Harrisburg, pp. 201-241.

Moore, J.A., 2002, Los Angeles. From genesis to genetics, University of California Press, s.l.

Morris, D., 1999, The naked ape, Delta, New York.

Pannenberg, W., 1977, Faith and reality, Search Press, London.

Peters, T. \& Bennett, G., 2002, Bridging science and religion, SCM Press, London. 
Pettit, P., 2011, The palaeolithic origins of human burial, Routledge.

Randolph-Quinney, P.S., 2015, 'The mournful ape: Conflating expression and meaning in the mortuary behaviour of Homo naledi', South African Journal of Science 11, 1-5.

Rovelli, C., 2016, Reality is not what it seems, Penguin Random House UK, Great Britain.

Ruse, M., 2001, Can a darwinian be a Christian?, Cambridge University Press, New York.

Tobias, P., 2013, Into the past, Memorial Edition ed., Picador Afria and Wits University Press, Johannesburg.

Van Huyssteen, J.W., 2004, Alone in the world? Human uniqueness in science and theology, William B. Eerdmans Publishing Company, Grand Rapids, MI.
Van Huyssteen, W., 1987, Teologie as kritiese geloofsverantwoording. RGN-studies in navorsingsmetodologie, Johann Mouton, Reeksredakteur, pp. 1-220.

Van Huyssteen, W., 1999, The Shaping of Rationality, Toward Interdisciplinarity in Theology and Science, William B. Eerdmans Publishing Company, Grand Rapids, Michigan

Van Huyssteen, W., 2008, 'Telling the story of religious awareness with interdisciplinary integrity from an evolutionary epistemological perspective', Scriptura 98, 222-230.

Von Rad, G., 1984, Genesis acommentary, Sixth impression edn., Fletcher \& Son Ltd., Norwich.

Ward, K., 2004, The case for religion, OneWorld, Oxford, England.

Wilson, E., 2012,The social conquest of the earth, Liveright Publishing Corporation, New York. 